\title{
Design and simulation of an equipment for the rehabilitation of people affected by ACV, starting from the subacute stage
}

\begin{abstract}
Cerebrovascular Accident (CVA) or stroke is a disease that results in paralysis of one side of the body. Physical therapy is generally used as a muscular rehabilitation tool that involves different techniques and exercises. For it to be effective, the process must be accompanied by the constancy and discipline with which the routines are performed, which are frequently limited to the hospital environment, causing an interruption in the development of recovery due to the absence of home mechanisms that facilitate its execution in a safe and complete manner. In Colombia, these aspects are enhanced by intervening factors such as: extensive travel from rural areas to care sites, accessibility to specialized centers, among others. That is why this article provides the proposal of an equipment that contributes to CVA rehabilitation from the subacute stage. The design and operation were developed and simulated through Solidworks 2018 Software, involving a series of exercises for upper and lower limbs considered by physiotherapists as of high importance in the treatment of the disease; it means, they can be executed by the patient under ergonomic and safety conditions.
\end{abstract}

\section{KEY WORDS}

Cerebrovascular accident, stroke, rehabilitation, design, simulation, mechanism

\author{
Yuly Jimena \\ González Rodríguez ${ }^{1}$ \\ Geraldine Pulido \\ Morales ${ }^{1}$ \\ Carlos Augusto \\ Toledo Bueno ${ }^{2}$ \\ ${ }^{1}$ Universidad Distrital Francisco \\ José de Caldas, Bogotá, Colombia. \\ Industrial Engineering \\ Department Student \\ ${ }^{2}$ Universidad Distrital Francisco \\ José de Caldas, Bogotá, Colombia. \\ Industrial Engineering \\ Department Professor \\ Corresponding author: \\ Yuly Jimena González Rodríguez \\ e-mail: \\ yjgonzalezr@correo.udistrital.edu.co
}

First received: 27.4.2021

Accepted: 20.7.2021.

\section{Introduction}

Cerebrovascular accident (CVA) or stroke is a disease of great concurrence in the world, with a total of 15 million people affected per year, according to data provided by the World Health Organization (WHO) (Puentes Madera, 2014) becoming the second cause of death with approximately 6.2 million deaths per year (correspond- ing to $10.6 \%$ of global mortality) and the third cause of life years lived with disability (Colombian Ministry of Health,2015), of which at least $30 \%$ of survivors develop incomplete recovery from functional impairment, and approximately an additional $20 \%$ require assistance with activities of daily living (Escudero et al, 2011). In Latin America, CVA has become the second leading cause of mortality with rates of $43.1 \%$ per 100,000 inhabitants 
(El Espectador Newspaper,2018), which is higher than in countries such as the United States where the figure is around 18\% (Newport, 2006) This may be associated with socioeconomic factors, leading countries with higher per capita income to offer more and better-quality stroke prevention measures. Particularly in Colombia, this disease has become the main cause of disability with 250,000 people affected and 45,000 new cases of stroke each year. (El Espectador Newspaper, 2018)

Cerebrovascular accident consists of the generation of tissue necrosis because of inadequate blood supply to a cerebral area, caused either by an obstruction due to the presence of clots or by the rupture of a blood vessel.

When the blood flow decreases, a loss of oxygen and nutrients that the brain receives and needs to carry out its functions is generated. For this reason, health conditions arise, ranging from the difficulty to raise the hands, to speak or the most representative one: the unilateral paralysis of the body. Point on which this work will be based, since only $6 \%$ of the affected people reach a total rehabilitation. (Arias, 2009)

Bearing this in mind, it is important to emphasize that the process is based on three stages: acute, subacute, and state. The first one represents a higher risk and patients present loss of consciousness, so they are generally bedridden. It can be interpreted as the time the person remains hospitalized. The subacute stage is the most important because that is the one in which it must be intervene. to recover the motor capacity in the medium and long term because the muscles are tense, and an increase of involuntary reflexes is generated. Finally, there is the period of state, the patient already has a greater degree of mobility and balance. However, it is necessary to continue the established exercise routine to obtain the highest degree of rehabilitation of the patient, and it depends on each specific case. (Arias, 2009)

Currently, the stroke rehabilitation process in the country is supported by physiotherapy, through mechanotherapy equipment (Mayor et al., 2018) and physical means, tries to reduce motor impairment and strengthen the affected nerve signals. There are rehabilitation centers such as Mobility Group that uses various equipment focused on physical rehabilitation, some of these mechanisms are (Mobility Group, n.d.).

Amadeo: passive rehabilitation equipment to stimulate hand mobility and strength.

Lokomat Pro: in charge of stimulating the patient's bone strength and gait performance.

Balance Trainer: it uses visualization and biofeedback resources to promote the recovery of balance and facilitate the patient's bipedalism.
In addition, there are several multimedia apps supported by virtual reality, which contribute to motor and cognitive recovery.

However, physiotherapeutic services offer for this condition is scarcely treated in medical centers with a schedule of 30 therapies on average, given the experience, but they are not enough depending on the case. Thus, to require a greater amount of private physical therapy is not a viable option for users; due to economic factors, displacement, insufficient knowledge in topics such as mechanotherapy, low affordability of equipment to facilitate the execution of the exercise routines established by the physician in a home space where the user can work in a complementary way with the activities performed with the physical therapist, as well as the autonomous work after the personal therapies are finished. All these factors limit the rehabilitation process and decrease the speed and effectiveness of the patient's recovery.

Considering the above, it is expected to design a mechanical equipment that allows people affected by stroke to perform their physical therapies at home, complementing the rehabilitation process in patients who are in post-acute stages. And integrating fundamental exercises that allow the autonomous work of the user and lead to an adequate recovery.

\section{Methodology}

The team has been structured along several stages, starting with the information gathering. To this end, the research starts with the characterization of the disease from a general view, covering topics such as: causes, symptoms, sequelae, and treatment. The articles were searched in various databases like Scielo, Dialnet, Scoopus, among others, as well as in the Colombian Ministry of Health and Social Protection website. From the previous search, some found articles contribute to learning about the types of stroke. CVA can be ischemic and hemorrhagic with a probability of occurrence of $80 \%$ and $20 \%$, respectively (Arias ,2009), The first is caused by the obstruction of an artery and the second by the rupture of the same. Also, the causes and different stages that the patient goes through during the disease (acute, subacute, and state) mentioned above.

Consequently, the contextualization was made from a quantitative perspective. It started worldwide, then Latin America and finally in Colombia. These data were provided by various bibliographical sources such as scientific articles, news, and designed guidelines by institutions in the country. The Clinical Practice Guide stipulated (Colombian Ministry of Health, 2015) is highlighted because it is useful to understand the impact that stroke has on the nation and its treatment. This topic was necessary to deepen through the investigation of 
the various rehabilitation centers in the cities, as well as the affordability of the therapies provided in them, as a continuation of the sessions given directly in the health centers. From this it was possible to identify the weakness that Colombia has regarding the implementation of mechanotherapy, due to its high importance in the rehabilitation of disabling diseases. There are some rehabilitation entities, among them Mobility Group that have several specialized teams. However, these centers present difficulties because they do not have several headquarters, and they are in the big cities. This makes it difficult for people who live in rural areas and increases the costs involved in individual therapies.

After recognizing the context of the disease in Colombia, the investigation of the exercises used in physical therapies corresponding to the rehabilitation of a stroke begins was made by sources such as YouTube, articles and direct communication with health professionals and affected patients. There was a special case of a 86-years-old adult who suffered an episode of stroke in mid-April 2018, caused him hemiplegia (paralysis) of 50\% of his bod. It affected his left side and prevented him from sitting, standing, and walking. Around 30 physical therapies were performed during the first months after the stroke, 12 of them performed by the EPS and 18 by private ones, because the patient had not reached a high degree of recovery and required more therapies. It was necessary to complement the process with exercises at home. They consisted of adapting elements or equipment from home such as bands, pulleys and balls and they required the assistance of a family member and the occasional supervision of a physiotherapist. These exercises were mainly aimed at recovering the strength and sensitivity of the patient's upper and lower limbs. And they were performed constantly on a regular basis of 3 or 4 times a week. Thanks to the family support and the adaptation of this equipment at home, an $80 \%$ recovery of mobility on the left side was achieved. It is a high number considering his age and the strong impact of the disease. However, it is important to recognize that this is not the case all the time. There are some factors that cause that the patient fails to recover mobility and even become permanently disabled like the patient's displacement to the place where the therapies are performed, the number of therapies assigned are not enough, and the lack of time for supervision and accompaniment by the family members.

The previous collection of theoretical and practical information aims to identify the problems regarding the care of patients, and identify the exercises used throughout the recovery process. Therefore, the classification of these exercises is carried out according to the part of the body that they stimulate: upper limbs, lower limbs, and trunk. The Guide for patients and caregivers of the University Hospital of Gran Canaria (Deniz et al, 2007) was used to select the exercises most used by physiotherapists (after several interviews with them) and in this way reduce the number of exercises to those that are essential for rehabilitation; those that can be carried out by the patient in a home environment; those that correspond to each of the stages of recovery; and those that are adaptable to the equipment to be designed. Also selecting the stages that this project will concentrate: the subacute and the state ones because the patient shows greater mobility.

Mirror therapy and its importance in stroke rehabilitation was also investigated since it improves the motor performance of the therapy through imitation between limbs. According to the article by Cepeda Vega \& Gómez Blanco (2011) Review on the Effectiveness of Mirror Therapy in the Rehabilitation Process of Upper Limbs in Patients with Stroke, mirror neurons correspond to $20 \%$ of the neurons present in the brain and are responsible for perceiving the reflection of movement and activating the contralateral hemisphere of the limb used, increasing the cortico-muscular excitability of the affected area.

Once the exercises were selected in the previous step and to better understand the methodology used for the execution of the movements and to implement them properly in the design of the equipment, videos were recorded showing the performance of the exercises by the members of the project. These were sent to physiotherapists for review and approval, obtaining the following list:

\section{Upper Limbs}

- Vertical elbow flexion-extension

- Finger extension

- Crossed elbow flexion-extension

\section{Lower Limbs}

- Ankle flexion and extension

- Knee flexion and extension

Based on the previous exercises, the design of the necessary mechanisms and the subsequent simulation of the movements through software was started.

\section{Proposed design for ACV rehabilitation equipment}

The selected exercises were investigated and corroborated by specialists in the field, so that they would represent an adequate complement for the patient's recovery after a stroke. The execution of the same is given through mechanisms that adapt to a conventional wheelchair, since it allows the user to move safely and perform the routines assigned in different spaces and 
schedules. Following a design that offers independence in each of the movements and promotes their frequency of execution and thus the integrity of the recovery.

Ergonomics is one of the most important fields when designing rehabilitation equipment, as it is responsible for relating products and environments to the needs and limitations of human beings (Aquino,2018) in order to offer attributes of safety, comfort and efficiency (Lascano Herrera, 2011); given the NTC (Colombian Technical Standard) 3955 of 1996: Definiciones y conceptos ergonómicos (Instituto Colombiano de Normas Técnicas y Certficación, 1996), product ergonomics should make use of different principles that allow the satisfaction of customer requirements, offering adequate risk control parallel with efficiency.

Therefore, for the present design, ergonomic parameters are taken into account to provide the patient with appropriate mechanisms for their body, contributing to the preservation of their wellbeing while exercising.

One of the characteristics of the design corresponds to the exercise of both sides of the body, with a view to stimulating the patient's mirror neurons. These neurons are directly related to functions such as learning new skills, imitation, theory of mind and reading intentions (Cepeda Vega \& Gómez Blanco, 2011). This process is presented because of the activation of the opposite hemisphere of the body. For this purpose, the equipment has a total of four mechanisms: two of them are in the lower limb area and the others in the upper limb area. This generates the movements corresponding to each of the selected exercises. In such a way that the patient executes them based on the strength of the unaffected body part. The patient follows a series of instructions for use that will be given later and that will be repeated until the number of cycles recommended by the physiotherapist has been completed. It is important to highlight that the mechanisms were designed in such a way that they do not generate discomfort in their use and can be executed simultaneously if authorized by the specialist. In addition, they can be inserted or removed from the wheelchair according to the patient's needs.

The design process began with the development of several sketches about the preliminary ideas of the mechanisms associated with each of the exercises, and their integration into the wheelchair. Then the dimensions and details of operation, and the simulation of the movements using the 3D modeling Solidworks 2018 Software were established. This software also allowed the obtaining of the drawings according to the metrics chosen for each one of them, using the International System of Units in millimeters $(\mathrm{mm})$. The equipment was designed based on the following terms mentioned in NTC 5654 of 2008, which establishes the general requirements for the establishment of an anthropometric database:
Anthropometric data: Measures that correspond to length, height, width, among other dimensions of the human body. (Instituto Colombiano de Normas Técnicas y Certficación, 2008)

Percentile: Statistical distribution in which the elements of an initial sample are assigned to various groups. (Instituto Colombiano de Normas Técnicas y Certficación, 2008)

Taking into account the above definitions, the anthropometric measurements belonging to the 5, 50 and 95 percentiles for men and women between 20 and 59 years of age in the Colombian population for the different areas of the body treated, from which the average of each percentile was calculated for the corresponding measurement (equation 1), obtaining a series of values that were used as a reference interval (lower limit corresponds to the average of the 5 percentile and the upper limit to the average of the 95 percentile), presenting changes in some measurements derived from the construction of the mechanisms, taking into account ergonomic parameters, so as to avoid injuries at the musculoskeletal level and reduce the effort that the patient makes when executing the different movements.

$$
\overline{\mathrm{x}}=\frac{x_{m}+x_{h}}{\mathrm{n}}
$$

$\overline{\mathrm{x}}=$ Average

$X_{m}=$ Corresponding percentile measurement for women $X_{h}=$ Corresponding percentile measurement for men $\mathrm{n}=$ total measures used per calculation

The design of the equipment was based on the current regulations for the application of measurements of a standard wheelchair. These are registered in ISO 7176-5:2008 (International Organization for Standardization, 2008) (determination of dimensions, mass, and maneuvering space) and ISO 9999:2007 (International Organization for Standardization, 2007) (support product for people with disabilities) The mechanisms were adapted to the parameters given in them and considering studies that cover the anthropometric measurements of the Colombian population in an age range between 20 and 59 years old. (Avila Chaurand, Prado Leon \& González Muñoz, 2015) and measures associated with Lower Limbs (Landines Jiménez, Nieves Pimiento \& Toledo Buenco, 2019).

The following is a description of the exercises proposed in the equipment and the mechanisms involved, figures corresponding to the planes and the movement described in each one of them are presented:

\section{Upper Limbs}

The upper limb area is divided into several exercises that are supported by straps and levers that allow movement 
in the magnitude chosen according to research and advice with specialists. Specific measures are also used for each of the exercises proposed, as shown below:

\section{Vertical Elbow Flexion-Extension}

The elbow is understood as an essential part for the execution of different important tasks in the daily life of the patient as feeding, cleaning, among others. Which is why the stimulation of the muscles corresponding to this area is vital for an adequate rehabilitation of the upper limbs. Therefore, the implementation of flexion and extension exercises in the proposed design is the main reason for this.

\section{Proposed Design for Flexion-Extension for Vertical Elbow}

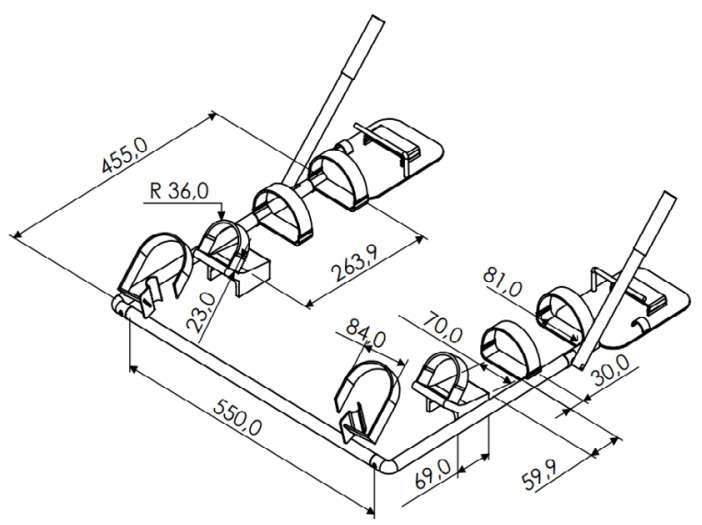

» Figure 1: Elbow Flexion-Extension Drawing

To perform the elbow flexion-extension, the equipment is arranged with a total of three upper straps for each arm, located in fingers, wrist, forearm, and arm. This is to provide stability and grip of the patient's limb (Figure 1). There are a few integrated parts that are governed by standard measures regarding the length of the wheelchair, as well as metrics corresponding to the purpose of the exercise, especially in the width. It is necessary to cover the backrest of the chair and at the same time to provide enough space for the location of the arms and thus offer free movement. On the other hand, there are the support straps at specific distances to give grip in specific areas of the extremities.

\section{Operation of vertical Elbow Flexion-Extension Mechanism}

The patient should place the hemiplegic arm in supination position (the palm of the hand is facing upwards) and adjust the straps in the places already mentioned in a way that the arm obtains a position of approximately $90^{\circ}$. The same procedure should be performed with the opposite extremity, except strap fingers so that achieved in supination grab the upper rod located on the plate and lift in a range of $0^{\circ}$ to $90^{\circ}$ approximately. This will drive the elevation of the affected arm, as it was presented in Figure 2.

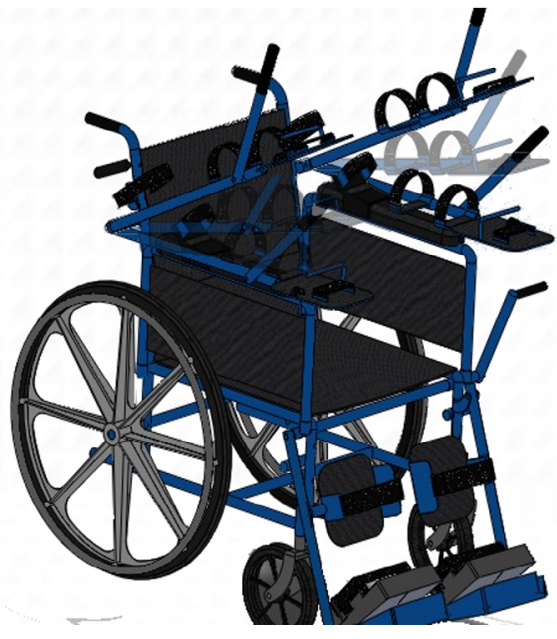

» Figure 2: Simulation of Elbow

Flexion-Extension Movement

Ergonomic and anthropometric considerations of vertical Elbow Flexion-Extension

The identification and use of the average values of the anthropometric measurements investigated (Avila Chaurand, Prado Leon \& González Muñoz, 2015) as the basis of the equipment and specifically in this exercise, allows us to provide the patient with a comfortable design in accordance with their upper limbs that allows the execution of the movements in an efficient manner, therefore taking into account the different percentiles mentioned, the main measurements calculated and obtained for the construction of the design of the mechanism are presented in Table 1.

\section{Table 1}

Average anthropometric measurements of the 5, 50 and 95 percentiles for the Colombian population for vertical elbow flexion-extension exercise

\begin{tabular}{l|c|c|c|c}
\hline \multirow{2}{*}{ Variable } & \multirow{2}{*}{ Equipment $(\mathbf{m m})$} & \multicolumn{3}{|c}{ Percentiles $\overline{\boldsymbol{x}} \mathbf{m m})$} \\
\cline { 3 - 5 } & & $\mathbf{5}$ & $\mathbf{5 0}$ & $\mathbf{9 5}$ \\
\hline Forarm length & 455 & 227 & 239,5 & 254 \\
\hline Fixed arm width & 84 & 87,4 & 99,9 & 112,8 \\
\hline Elbow width & 70 & 58,5 & 64 & 70,5 \\
\hline Width of the back & 550 & 397 & 441 & 489,5 \\
\hline Flexed arm height & 59 & 40,1 & 46,7 & 55 \\
\hline
\end{tabular}

Some of the final measurements of the mechanism may exceed the proposed range due to the construction requirements of the mechanism, converting them into measurements of the equipment itself, however these do not jeopardise the comfort and safety of the user as they are supported by accessories such as straps and supports that provide firmness and the necessary grip.

The arms are initially in extension at an angle of $0^{\circ}$ with respect to the height of the armrest so as not to 
generate imbalance to the sides or muscular overstrain, ensuring that at the time of executing the exercise an angle with a range of $0^{\circ}$ to $60^{\circ}$ is reached in the seated position and the extension movement when it returns to its initial point on the armrest; the angle is calculated from the initial goniometric conditions given in the book Goniometría: A tool for the assessment of occupational disabilities (Taboadela, 2007) which are $0^{\circ}$ to $150^{\circ}$ in decubitus-dorsal position. The location of the armrest also allows the location of the supports in the wrist, mid-forearm and elbow areas at the correct lengths from each other, as these are points that, given the research with physiotherapy specialists and the review of the Guide for patients and carers (Deniz Cáceres et al, 2007), offer stability to the forearm and keep it in a suitable position for exercise, preventing it from becoming dislocated and injured due to the after-effects of the stroke, which can lead to muscle retraction, while respecting the patient's own capacity.

It should be noted that the elbow support is designed to fit the length of the forearm of the Colombian population in the age range of 20 to 59 years, ensuring that it is a safe and stable area for the positioning of the forearm.

The mechanism used allows the patients to elevate the arms in the range that they can do according to their current motor skills. This prevents the patients from overstraining their muscles and allows them to perform the movements safely. This feature is an advantage of the proposed design.

\section{Finger Extension}

Motor skills allow to perform most daily activities such as fine motor skills. These skills are affected in cases of stroke. To mitigate those impacts, finger extension exercise will be available to counteract stiffness and "claw hand" syndrome (fingers drawn inward into the hand) (Sentandreau Mañó et al, 2011), contributing to the therapies performed by the specialist.

\section{Proposed Design for Finger Extension}

This exercise was designed based on measurements obtained through the investigation of anthropometric studies in the Colombian population regarding the area of the hands (Avila Chaurand, Prado Leon \& González Muñoz, 2015), including length, width, and separation between fingers. As it was shown in Figure 3. This is a unique feature of the equipment, so these measurements cannot be found in the regulations of a standard wheelchair, but they were structured to provide safety and comfort to the patient.

By assigning measurements for the mechanism, it was possible to determine the quantity and position of each part involved in the design and operation. At the end, the desired results for the finger extension were obtained.

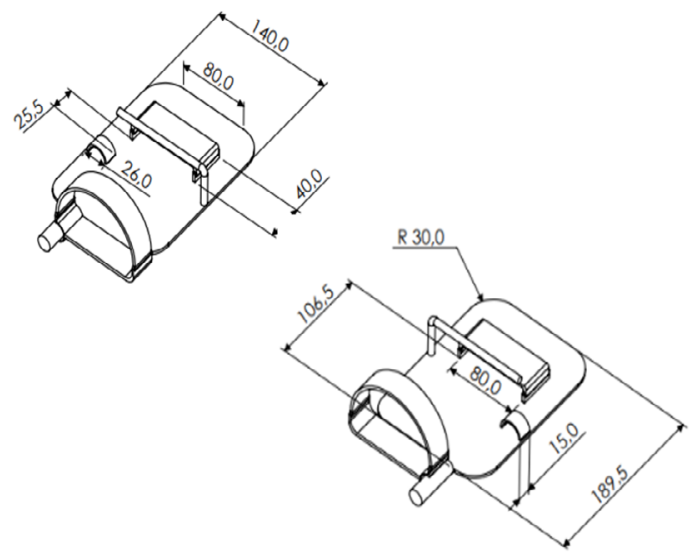

» Figure 3: Finger Extension Drawing

Operation of Finger Extension Mechanism

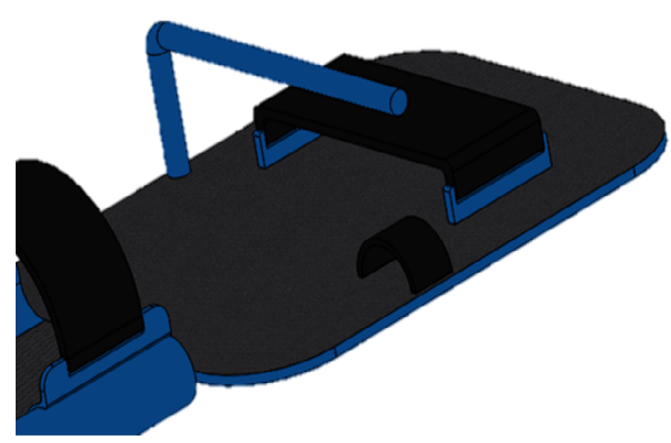

» Figure 4: Extension Finger Mechanism

To perform this exercise, as shown in Figure 4, the equipment has a plate and two straps, one for each hand and additional supports for each extremity that correspond to those used in elbow flexion-extension. Patients will place their hemiplegic forearm on the supports and the palm of the hand is extended upwards (supination position). With the help of one of the straps located on the plate, four of the fingers of the palm of the affected hand will be held and with the other the thumb, keeping it separated from the others and causing a stretching of them. The opposite hand, since it has movement, does not require this adjustment procedure. Therefore, the mechanism has an upper rod that serves as an impulse base for elbow flexion-extension, as mentioned above. However, it was installed on both sides to facilitate patients' execution of the movements, carrying out an imitation and support process. Likewise, it allows the execution of finger extension independently of the hemiplegic side.

\section{Ergonomic and anthropometric considerations of finger extension exercise}

The average main values used as a basis for the finger extension exercise are focused on the hand area, 
so length, hand width and finger measurements are taken into account, as shown in Table 2:

\section{Table 2}

Average anthropometric measurements of the 5, 50 and 95 percentiles for the Colombian population for finger extension exercise

\begin{tabular}{l|c|c|c|c}
\hline \multirow{2}{*}{ Variable } & \multirow{2}{*}{ Equipment $\mathbf{( m m )}$} & \multicolumn{3}{|c}{ Percentiles $\overline{\boldsymbol{x}} \mathbf{( m m})$} \\
\cline { 3 - 5 } & & $\mathbf{5}$ & $\mathbf{5 0}$ & $\mathbf{9 5}$ \\
\hline Length of hand & 189,5 & 161,5 & 174,5 & 189,5 \\
\hline $\begin{array}{l}\text { Length of the } \\
\text { palm of the hand }\end{array}$ & 106,5 & 88,5 & 97,5 & 106,5 \\
\hline Hand width (plate) & 140 & 73 & 79,5 & 86 \\
\hline Finger length & 80 & 73 & 79,5 & 86 \\
\hline
\end{tabular}

In this case some measurements coincide with the upper limit of the interval and others like the width of the hand are superior, this is because by including in the plate elements such as straps and supports the amplitude should increase, however the space intended for the positioning of the hand is the necessary, allowing the exercise to be executed with freedom and comfort.

The main plates are designed to keep the thumb at an angle between 0 to $20^{\circ}$, which is the normal interval of abduction, and the other fingers at a position of $0^{\circ}$ (Taboadela, 2007), providing through the strap in those areas, the strength to maintain the extension of the fingers when the hand does not possess its own resistance due to the hand-in-claw syndrome caused by spasticity affecting the metacarpophalangeal joints (Monreal González et al, 2016) in addition to the wrist support point, which is equipped with a soft base in order not to cause sores, respecting the freedom of the patient to lift the straps according to their muscle capacity.

\section{Shoulder Flexion}

The shoulder is one of the parts most affected after a stroke. This is because since the muscle is in a flaccid state, it is unable to maintain the head of the humerus in the glenoid fossa, causing a subluxation (displacement out of the corresponding cavity). This is usually evident two to three months after the episode and it is considered one of the most common sequelae. Some patients experience pain and have difficulty in performing basic activities. For this reason, it is important to work on the recovery of this area and while the overall rehabilitation process is facilitated.(Murie Fernández et al, 2012).

\section{Proposed Design for Shoulder Extension}

Since it makes use of a support lever, this exercise is not supported with specific normative measures as those initially consulted, because it has new mechanisms in this type of chair. Taking as reference anthropometric measurements corresponding to the length of the arm and the angles of elevation of the same becomes necessary. As well as using as a guide the metric for the flexion-extension movement parts, as shown in Figure 5.

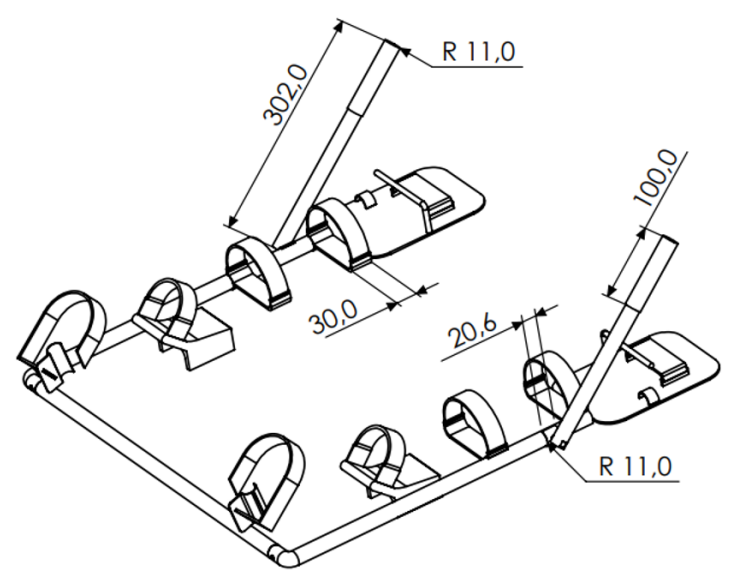

» Figure 5: Shoulder Flexion Drawing

With the given measurements, the inclined lever is arranged so that the patient's arm is extended in the proper position for the exercise and the desired movement is performed.

\section{Operation of Shoulder Flexion Mechanism}

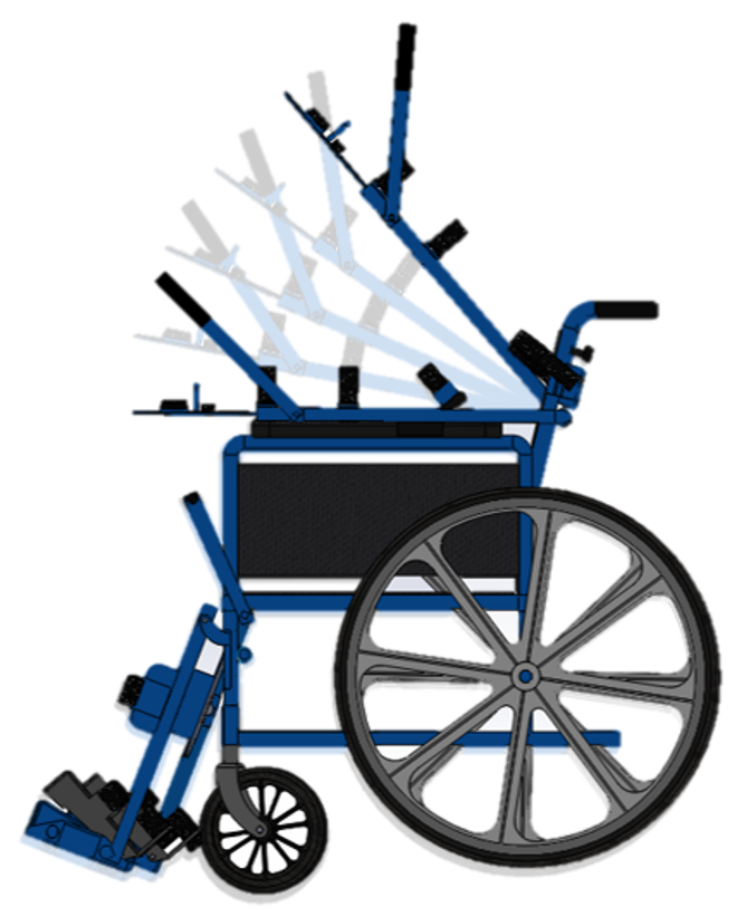

» Figure 6: Simulation of Shoulder Flexion Movement

The device has a lever inclined at $45^{\circ}$ with respect to the hand plate corresponding to the upper extremity mechanism. The patient will be able to grasp the handle and raise it to a comfortable amplitude as shown in figure 6 . Nevertheless, the design allows a maximum movement of $58.5^{\circ}$ due to the angle of inclination is 
discounted. This leads to the arm being positioned at an ideal angle of $90^{\circ}$ or in the limit case $103.6^{\circ}$ to the origin.

The lever is on both arms. This allows the patient to perform the exercise independently of the affected side, thus supporting the mirror therapy. It is important to remember, particularly in this exercise, that the lever can be removed if it is necessary.

\section{Ergonomic and anthropometric considerations of shoulder flexion exercise}

The shoulder has three elementary movements which are: elevation (combined flexion movement, abduction and external rotation), external rotation and internal rotation. In this case the team performs the flexion movement which consists of the lifting of the arm in the sagittal plane (Fierro, n.d.) and the return to its initial position on the wheelchair for which some measures shown in Table 3 are taken as reference:

\section{Table 3}

Average anthropometric measurements of the 5, 50 and 95 percentiles for the Colombian population for shoulder bending exercise

\begin{tabular}{l|c|c|c|c}
\hline \multirow{2}{*}{ Variable } & \multirow{2}{*}{ Equipment $(\mathbf{m m})$} & \multicolumn{3}{|c}{ Percentiles $\overline{\boldsymbol{x}} \mathbf{( m m )}$} \\
\cline { 3 - 5 } & & $\mathbf{5}$ & $\mathbf{5 0}$ & $\mathbf{9 5}$ \\
\hline Arm length & 601,38 & 674,5 & 709 & 750,5 \\
\hline Hand width & 100 & 73 & 79,5 & 86 \\
\hline
\end{tabular}

For the execution of the exercise it is not necessary to use straps on the forearm and arm, since holding the inclined lever requires the full extension of the arm and the width of the hand when holding it, so that the user only has to lift it with his unaffected arm to generate movement in both arms.

The arm length protrudes from the measurement range described in Table 3 due to the tilt of the lever, as the $45^{\circ}$ angle provides an additional stretch distance that complements the arm length so that it is attainable to the user, and the hand support of the lever allows the patient from his grip ability to have enough amplitude to hold it.

This is a passive-active base exercise, as the user runs it without intensive assistance from the equipment, so the conditions of lever angle and grip width give the patient the freedom of stretching without overexerting the muscles.

\section{Lower Limbs}

\section{Knee Flexion-Extension}

The stimulation of the knee is an essential step for the reeducation of the body in the walking activity. Therefore, the execution of flexion-extension of the knee is proposed as one of the main movements of the equipment to encourage full recovery of the patient. (Nogueras et al, 2016).

Proposed Design for Knee Flexion- Extension

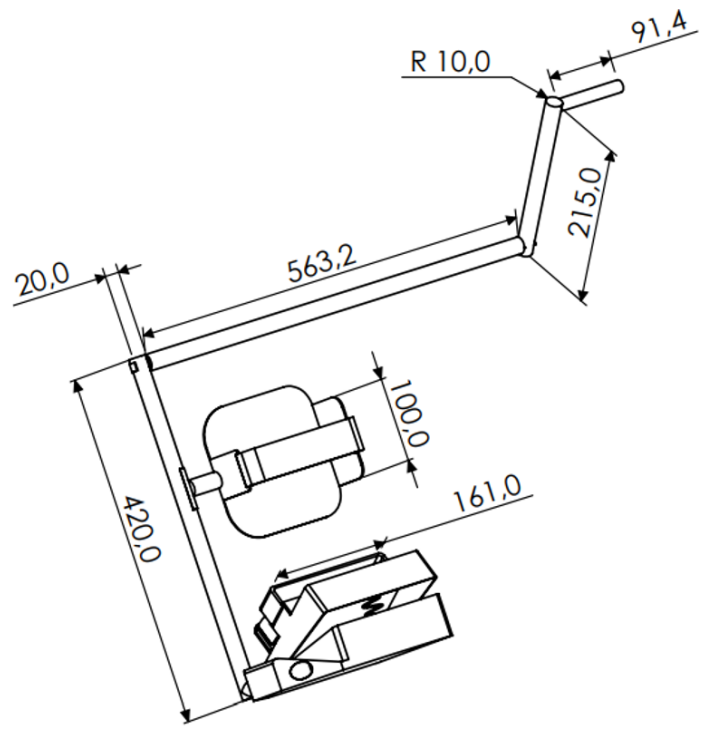

» Figure 7: Drawing of Knee Flexion-Extension of the Affected Leg

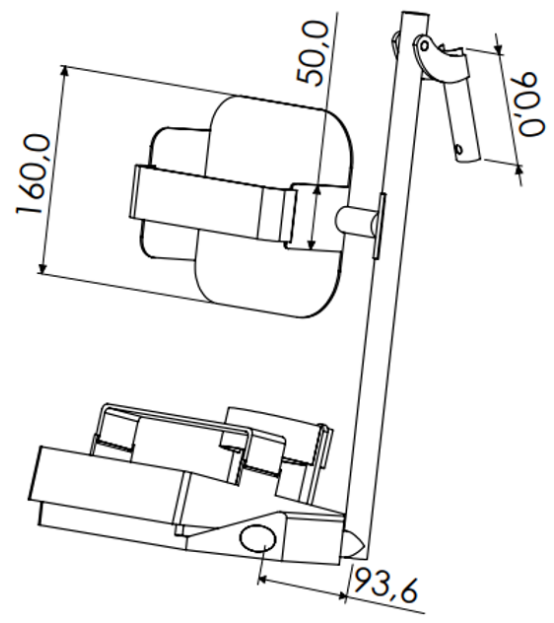

» Figure 8: Drawing of Knee Flexion-Extension of the Non-Affected Leg

For the design of this exercise, the standard measurements corresponding to the length of the leg, height limit to the armrest, and width were taken as a base. 
Nonetheless, some modifications were made to these measurements, for the mechanism to accommodate properly and execute the movement without interfering with the original frame of the wheelchair or causing discomfort to the patient. To get a metric as shown in Figures 7 and 8.

For the straps and grips, special attention is given to the anthropometric measurements already investigated regarding leg width and desired coverage distance for the support, as well as lever support and lever height.

\section{Operation of Knee Flexion-Extension Mechanism}

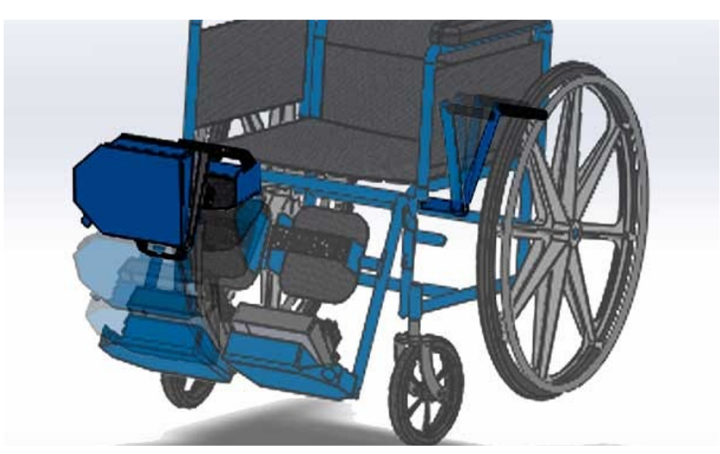

» Figure 9: Simulation of Knee Flexion-Extension Movement

The equipment reproduces the movement associated with this exercise through the transmission of forces, which find their origin in the main lever located on the unaffected side of the patient. This lever is pushed backwards with the hand, causing the hemiplegic leg support to rise to a maximum angle generating the extension movement. It is important to know that for this case, the range of motion is $69^{\circ}$, since the leg support is inclined at $21^{\circ}$, so that it does not collide with the front tires of the chair. This is accomplished from the starting point to the horizontal position of the limb, making an angle of $90^{\circ}$ with the ground.

Knee flexion is produced by bringing the main lever back to its initial position. The bracket descends according to the force applied to the hand by the patient, until it returns to the zero point. This aspect gives patients the freedom to flex and extend in a range of motion that is comfortable for them.

For the unaffected leg, the lifting process is different. It occurs with the force applied to the same limb. The patient should lift the leg and descend so that the exercise is executed, and the hemiplegic part can mimic the movement accordingly as shown in Figure 9.

To secure the patient and corroborate the proper execution of the exercise, the mechanism has two straps. These work as support for the limb, located in the middle of the leg and ankle. At the same time, they collaborate with the flexion and extension of the ankle.

It is important to emphasize that the patient must adjust the straps before performing the movement, to provide the necessary support to the limbs. This step will be performed for both legs.

\section{Ergonomic and anthropometric considerations of flexo-knee extension exercise}

The average measurements used as the base of the flexo-knee extension mechanism focus on the lower limb and hip area, since they are necessary for the implementation of the mechanism, those with greater relevance being those observed in Table 4.

\section{Table 4}

Average anthropometric measurements of the 5th, 50th and 95th percentiles for the Colombian population for flexo-knee extension exercise

\begin{tabular}{l|c|c|c|c}
\hline \multirow{2}{*}{ Variable } & \multirow{2}{*}{ Equipment $(\mathbf{m m})$} & \multicolumn{3}{|c}{ Percentiles $\overline{\boldsymbol{x}} \mathbf{( m m})$} \\
\cline { 3 - 5 } & & $\mathbf{5}$ & $\mathbf{5 0}$ & $\mathbf{9 5}$ \\
\hline Hip width & 563,1 & 317,5 & 361 & 408,5 \\
\hline Radial height & 269 & 192 & 234,5 & 270,5 \\
\hline $\begin{array}{l}\text { Popliteal fossa } \\
\text { height }\end{array}$ & 420 & 369 & 403,5 & 440 \\
\hline
\end{tabular}

The measurements such as the width of the hip are outside the range raised in the percentiles because the mechanism has a base lever which must protrude from the seat of the chair in order to achieve the mechanical functioning of the same; however this additional length is not intrinsic to the central design of the chair but protrudes from it without affecting the limbs, additionally the angle between thighs and trunk is $90^{\circ}$ which allows for a correct postural support point for the patient providing stability to the pelvis (Barrientos, Sánchez \& García, 2016) and a length suitable for the extension of the leg, offering a support on the back of it that extends over much of the gastrocnemius muscle, providing firmness to the leg at the time of performing the exercise.

The knee has two fundamental movements, which correspond to flexo-extension and axial rotation, the latter occurs autonomously when flexion is executed. The team focuses the knee mechanism on the first movement, so an initial sitting position is taken into account, which involves a bending of $90^{\circ}$ and an extension of $0^{\circ}$.

The design allows a postural cushion to be placed on the seat when using the chair so that it is more comfortable when the movements are executed. 


\section{Ankle Flexion-Extension}

Among the complications that can occur in stroke, there are some articular affectations at the lower limb level, mainly foot drop, spastic clubfoot, and claw toes due to dystonia (involuntary contraction of the muscles) prevent the patient from having stability in his feet and thus achieve standing upright (Piera, Coulomb \& Renard Deniel, 2009).

Given these affectations, the need to exercise the foot and ankle safely and with a high degree of independence by means of the equipment arises. This allows flexion and extension by applying force to them. As well as how to maintain a proper position with the help of the straps.

\section{Proposed Design for Ankle Flexion-Extension}

The design of this exercise is based on the anthropometric measurements corresponding to the foot and two fundamental ankle movements which are flexion and extension. In the ankle flexion movement, the maximum angle was identified which is $50^{\circ}$ starting from a position of $0^{\circ}$, and a maximum extension movement of $30^{\circ}$ which also begins in $0^{\circ}$ (Taboadela, 2007)

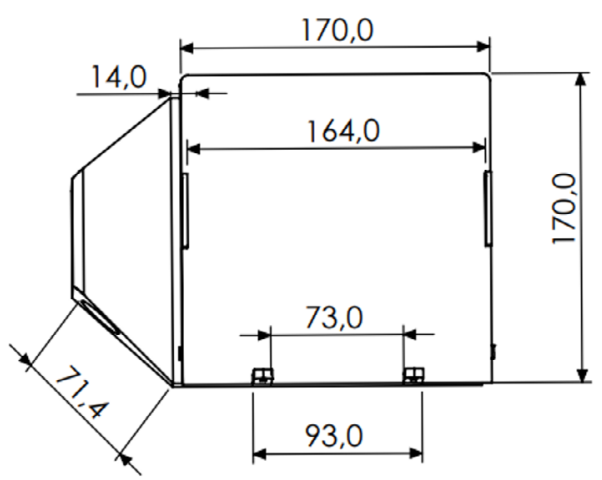

» Figure 10: Drawing of Ankle Flexion-Extension from Top View

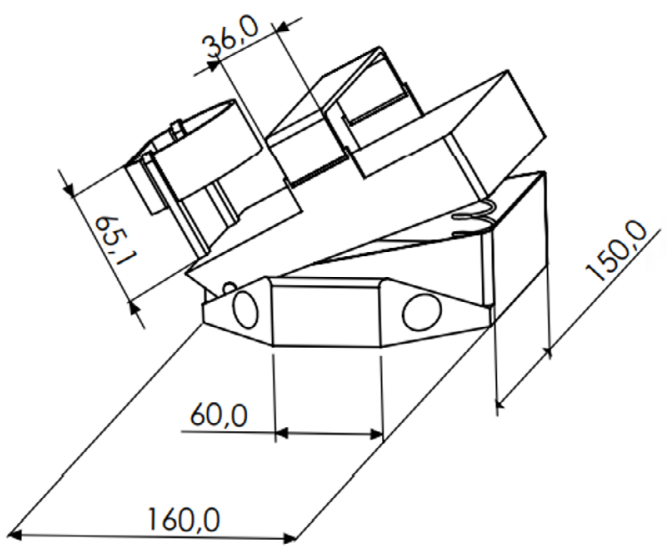

» Figure 11: Drawing of Ankle Flexion-Extension from Lateral View, Part 1

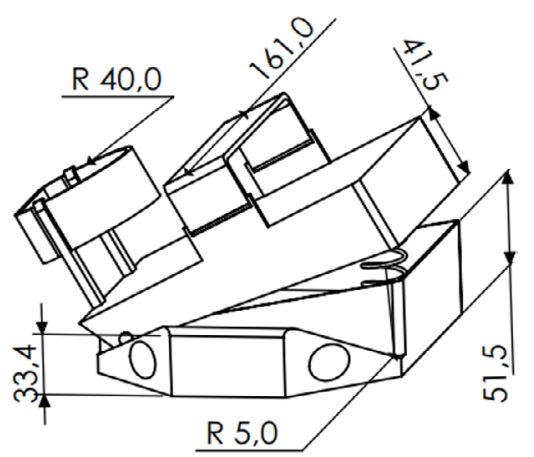

» Figure 12: Drawing of Ankle Flexion-Extension from Lateral View, Part 2

The foot measurements considered were the width and length, as well as the thickness of the ankle and the appropriate grip height for the execution of flexion and extension. On the other hand, the inclination of the pedals $\left(21^{\circ}\right)$ with respect to the wheelchair frame is defined according to the newly defined metric (Figures 10, 11 and 12). This allows the patient's limbs to be handled safely and comfortably at the angles established in the research for the movement.

\section{Operation of Ankle Flexion-Extension Mechanism}

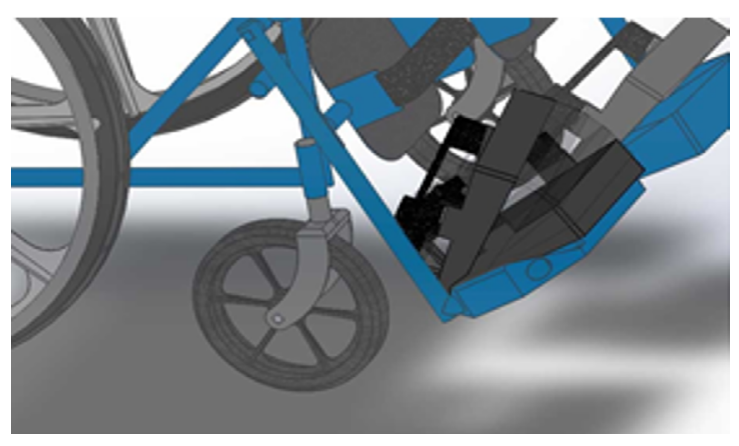

» Figure 13: Simulation of Ankle Flexion-Extension Movement

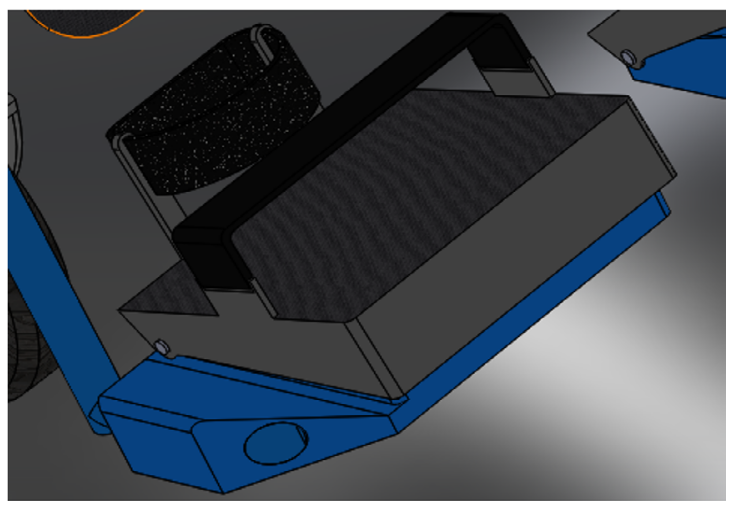

» Figure 14: Simulation of Ankle Flexion-Extension Movement 
The mechanism consists of a pedal that replaces the conventional footrest (found in the wheelchair) with one that uses a simple spring inside. This generates the ascent and descent of the pedal according to the force applied (Figure 13). The sole of the patient's foot is placed on the top of the pedal at $20^{\circ}$ in dorsiflexion, moving up to $5^{\circ}$ with respect to the base of the mechanism. This produces the extension movement as shown in Figure 14.

The equipment has two straps located on the right and left side. These straps are adjusted in the ankle and instep area to the foot acquires the proper position for the execution of the exercise.

\section{Ergonomic and anthropometric considerations of flexo-ankle extension exercise}

The area of the flexo-ankle extension mechanism is characterized by being designed with the patient suffering from stroke in mind, so the anthropometric measurements used as a reference are a basis of values modified according to the characteristics of the disease, noting that requirements such as the use of separate footrests to avoid friction between the legs are met, a heel length designed to cover up to the finger area so that the plant is supported, receiving support in the pressure provided by the straps located on the instep and ankle, points that are necessary for the stability of the foot and the proper position for the execution of the exercise since it allows an angle of $90^{\circ}$ between the ankle and the base of the pedal when no flexion or extension movements are made.

The width of the footrests is wide because the foot of the patient with stroke tends to lean towards the central area so it is important to maintain enough space for it and not force the movement causing pain, allowing the user and the physiotherapist to decide how much pressure they can receive from the supports.

Taking into account the above, the average measures used as a reference in this mechanism are shown in Table 5:

\section{Table 5}

Average anthropometric measurements of the 5, 50 and 95 percentiles for the Colombian population for the ankle flexion-extension exercise

\begin{tabular}{l|c|c|c|c}
\hline \multirow{2}{*}{ Variable } & \multirow{2}{*}{ Equipment $\mathbf{( m m )}$} & \multicolumn{3}{|c}{ Percentiles $\overline{\boldsymbol{x}} \mathbf{( m m})$} \\
\cline { 3 - 5 } & & $\mathbf{5}$ & $\mathbf{5 0}$ & $\mathbf{9 5}$ \\
\hline Foot width & 170 & 86,5 & 94,5 & 104,5 \\
\hline Heel length & 170 & 179,5 & 194 & 210 \\
\hline Ankle width & 62 & 60,7 & 67,6 & 75,2 \\
\hline
\end{tabular}

To conclude the description of the exercises, the different mechanisms described above are integrated to obtain the design shown in Figure 15.

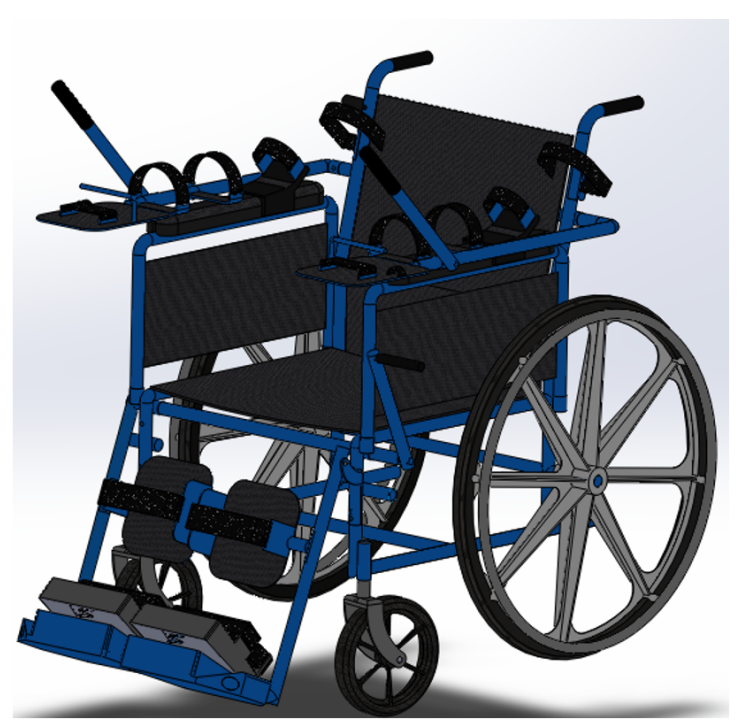

» Figure 15: Integrated Design of the Proposed Equipment for CVA Rehabilitation

\section{Conclusions}

The rehabilitation of a patient who has suffered a stroke depends on several factors. One of the most important is the performance and active participation of physical therapy. This therapy is a fundamental tool for the recovery of skills affected by the disease through the stimulation of muscles in aspects such as strengthening, mobility, among others. For the same reason, the design of equipment that works in environments other than the clinic allows the patient to develop the routines ordered by the professional more frequently. The patient will perform a set of five exercises selected through research and consultation with specialists. Those with the greatest impact on the affected areas were integrated.

The choice of the wheelchair as the basis for this equipment facilitated the insertion of mechanisms that correspond to each of the exercises. These exercises are based on standard metrics, according to the regulations, and the anthropometric measurements of the Colombian population. One of the advantages of this equipment is that any patient in the country can be coupled. The result of this equipment was designed in SolidWorks 2018 Software, which allowed to observe the movement of the mechanisms and the dimensions of each of the elements that make it up.

The advantages of this proposal are on the one hand, it offers patients the opportunity to perform basic rehabilitation exercises in different environments, such as their home. This is so that their recovery process is not interrupted, and they enjoy autonomy due to the ease of execution; just as the physiotherapist is absent. On the other hand, this equipment functions 
as a support for the health professional and not as a replacement of the same. It is also added to them, its ergonomic structure so that patients can perform the exercises simultaneously if they and the specialist wish.

The mechanisms were designed to be able to be inserted into a standard wheelchair and accommodate them depending on which side of the body is affected. At the same time, it allows exercising upper and lower limbs in the same equipment. This quality increases its usefulness, since usually the designs intended for specific CVA rehabilitation are focused on a specific area of the body or only one of them can be activated.

The proposed equipment is a proposal that is open to the incorporation of exercises corresponding to occupational therapy (relevant field in CVA rehabilitation) or elements that contribute to the facilitation and execution of the assigned physical therapy.

\section{Acknowledgments}

The work done by the physiotherapy Laura Carrillo Garzón and the Engineer Miguel José Pérez González for their guidance in the proper selection of rehabilitation exercises and the management of the software used is acknowledged.

\section{References}

Aquino Tapia, D. (2018) Terapía física en ergonomía laboral. Undergraduate thesis. Universidad Inca Garcilaso De La Vega.

Arias Cuadrado, Á. (2009) Rehabilitación del ACV: evaluación, pronóstico y tratamiento. Galicia Clínica. 70 (3), 25-40.

Avila Chaurand, R., Prado Leon, L. R. \& González Muñoz, E. L. (2015) Dimensiones antropométricas de población latinoamericana. Guadalajara, Universidad de Guadalajara.

Barrientos, F., Sanchez, J. \& Garcia, J. (2016) Diseño de una silla de ruedas de cambios postulares y posiciones basicas para personas. Undergraduate thesis. Escuela Superior de Ingeniería Mecánica y Eléctrica.

Cepeda Vega, L. C. \& Gómez Blanco, M. A. (2011) Revisión sobre la efectividad de la terapia en espejo en el proceso de rehabilitación de miembros superiores en pacientes con ACV. Movimiento Científico. 13 (2), 48-54. Available from: doi: 10.33881/2011-7191.mct.13205

Colombian Ministry of Health (2015) Guía de práctica clínica de diagnóstico, tratamiento y rehabilitación del episodio agudo de ataque cerebrovascular isquémico, en población mayor de 18 años. Available from: https://www.iets.org.
co/Archivos/46/GPC_ACV_Version_Final_Completa.pdf [Accessed: 2nd March 2020].

Déniz Cáceres, A., Álamo Arce, D., Ruiz Primo, C., Hernández López, M., Gómez García, A., López Fernández, J. \& Cubero González, A. (2007) Guía para Pacientes y Cuidadores: Ejercicios para hacer en casa después de un accidente Cerebrovascular. Available from: https:// terapiaocupacional50.files.wordpress.com/2007/12/ ejercicios-para-realizar-en-casa-despues-deun-acv.pdf [Accessed: 13th February 2020].

El Espectador Newspaper (28 October 2018) Derrame cerebral es la primera causa de discapacidad de adultos en Colombia. El Espectador Newspaper. Available from: https://www.elespectador.com/ noticias/salud/derrame-cerebral-es-la-primera-causa-de-discapacidad-de-adultos-en-colombia-articulo-820667 [Accessed: 4th March 2020].

Escudero Suárez, J. C., Restrepo Cano, S., Ramirez, E. P., Bedoya, C. L. \& Jiménez, I. (2011) Descripción clínica, social, laboral y de la percepción funcional individual en pacientes con ataque cerebrovascular. Acta Neurológica Colombiana. 27, 97-105.

Fierro, G. (n.d.) Movilidad del Hombro. Available from: https://guidofierro.com/academico/examen-fisico-de-hombro/movilidad-del-hombro/ [Accessed: 1st July 2021] Instituto Colombiano de Normas Técnicas y Certficación (1996) NTC 3955. Ergonomía. Definiciones y conceptos ergonómicos. Bogota, Instituto Colombiano de Normas Técnicas y Certficación.

Instituto Colombiano de Normas Técnicas y Certficación (2008) NTC 5654. Requisitos Generales para el establecimiento de una base de datos antropométricos. Bogota, Instituto Colombiano de Normas Técnicas y Certficación.

International Organization for Standardization (2007) ISO 9999:2007. Assistive products for persons with disability - Classification and terminology. Geneva, International Organization for Standardization.

International Organization for Standardization (2008) ISO 7176-5:2008. Wheelchairs - Part 5: Determination of dimensions, mass and manoeuvring space. Geneva, International Organization for Standardization.

Landines Jiménez, K., Nieves Pimiento, N. \& Toledo Bueno, C. A. (2019) Simulation of forces applied to the human femur: Analysis of finite elements. Revista vínculos. 16 (1), 73-81. Available from: doi: 10.14483/2322939X.15575.

Lascano Herrera, P. (2011) Diseño y construcción de una máquina de gimnasio para realizar rutinas de ejercicios con fuerza relativa. Undergraduate thesis. Pontificia Universidad Católica del Ecuador Sede Ambato. Mayor, J. J. V., Jiménez, N. J. V., Hoyos, G. P. A. \& Bravo, E. F. C. (2018) Sistema de Biofeedback para Rehabilitación de Marcha Asistida por un Exoesqueleto. Revista Ingeniería Biomédica. 12 (24), 50-59, Available from: doi: 10.24050/19099762.n24.2018.713 
Mobility Group (n.d.) Equipos Mobility Group. Available from: http://www.mobilitygroup.co/mobility/ page/equipos [Accessed: 9th March 2020].

Monreal González. R., Gómez Hernández. D., Faedo Castro, E. \& Osinaga Egüez, G. (2016) Modificación simplificada de la técnica de Zancolli para la corrección de la garra cubital. Revista Iberoamericana de Cirugía de la Mano. 44 (2), 91-96. Available from: doi: 10.1016/j.ricma.2016.08.006.

Murie Fernández, M., Carmona Iragui, M., Gnanakumar, V., Meyer, M., Foley, N. \& Teasell, R. (2012) Hombro doloroso hemipléjico en pacientes con ictus: Causas y manejo. Neurologia. 27 (4), 234-244. Available from: doi: 10.1016/j.nrl.2011.02.010.

Newport, R. (2006) Ventajas de la rehabilitación asistida mediante robot en la recuperación de las funciones motriz y visuoespacial en pacientes en fase de recuperación de un accidente cerebrovascular. Revista Española de Geriatría y Gerontología. 41, 66-73.

Nogueras, A. M., Arenillas, C. L., Rodríguez, O. F., Iglesias, B. C. \& Sánchez, S. C. (2016) Fases de la marcha humana, Human walking phases. Revista lberoamericana de fisioterapia y kinesiología. 2 (1), 44-49.

Piera, J. B., Coulomb, Y. \& Renard Deniel, S. (2009) Pie del adulto hemipléjico por accidente cerebrovascular. EMC - Podología. 11 (2), 1-12. Available from: doi: 10.1016/s1762-827x(09)70688-1.

Puentes Madera, C. (2014) Epidemiología de las enfermedades cerebrovasculares de origen extracraneal, Epidemiology of the cerebrovascular diseases of extracranial origin. Revista Cubana de Angiología y Cirugía Vascular. 15 (2), 66-74.

Sentandreau Mañó, T., Salom Terrádez, J., Tomás, J., Meléndez Moral, J., de la Fuente Fernández, T. \& Comapany José, C. (2011) Electroestimulación en el tratamiento de la mano hemipléjica espástica después de un ictus: estudio aleatorizado. Medicina Clínica. 137 (7), 297-301. Available from: doi: 10.1016/j.medcli.2010.10.024

Taboadela, C. H. (2007) Goniometría: Una herramienta para la evaluación de las incapacidades laborales. Buenos Aires, Asociart Art.

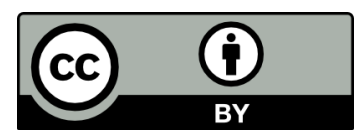

(C) 2021 Authors. Published by the University of Novi Sad, Faculty of Technical Sciences, Department of Graphic Engineering and Design. This article is an open access article distributed under the terms and conditions of the Creative Commons Attribution license 3.0 Serbia (http://creativecommons.org/licenses/by/3.0/rs/). 